\title{
Clinical study using mesenchymal stem cells for the treatment of patients with severe COVID-19
}

Lingling Tang, ${ }^{1, *}$, Yingan Jiang, ${ }^{2, *}$, Mengfei Zhu ${ }^{1, *}$, Lijun $\mathrm{Chen}^{3, *}$, Xiaoyang Zhou ${ }^{2}$, Chenliang Zhou ${ }^{2}$, Peng Ye ${ }^{2}$, Xiaobei Chen ${ }^{2}$, Baohong Wang ${ }^{3}$, Zhenyu Xu${ }^{4}$, Qiang Zhang ${ }^{4}$, Xiaowei $\mathrm{Xu}^{3}$, Hainv $\mathrm{Gao}^{1}$, Xiaojun $\mathrm{Wu}^{2}, \mathrm{Dong}^{2}{ }^{2}$, Wanli Jiang ${ }^{2}$, Jingjing $\mathrm{Qu}^{3}$, Charlie Xiang $(\bowtie)^{3}$, Lanjuan Li $(\bowtie)^{1,3}$

${ }^{1}$ The Shulan (Hangzhou) Hospital, Affiliated to Shulan International Medical College, Zhejiang Shuren University, Hangzhou 310022, China; ${ }^{2}$ Department of Infectious Diseases, Renmin Hospital of Wuhan University, Wuhan 430060, China; ${ }^{3}$ State Key Laboratory for Diagnosis and Treatment of Infectious Diseases, National Clinical Research Center for Infectious Diseases, Collaborative Innovation Center for Diagnosis and Treatment of Infectious Diseases, The First Affiliated Hospital, College of Medicine, Zhejiang University, Hangzhou 310003, China; ${ }^{4}$ Innovative Precision Medicine (IPM) Group, Hangzhou 311215, China

(C) Higher Education Press 2020

\begin{abstract}
The coronavirus disease 2019 (COVID-19) caused by SARS-CoV-2 was identified in December 2019. The symptoms include fever, cough, dyspnea, early symptom of sputum, and acute respiratory distress syndrome (ARDS). Mesenchymal stem cell (MSC) therapy is the immediate treatment used for patients with severe cases of COVID-19. Herein, we describe two confirmed cases of COVID-19 in Wuhan to explore the role of MSC in the treatment of COVID-19. MSC transplantation increases the immune indicators (including CD4 and lymphocytes) and decreases the inflammation indicators (interleukin-6 and C-reactive protein). High-flow nasal cannula can be used as an initial support strategy for patients with ARDS. With MSC transplantation, the fraction of inspired $\mathrm{O}_{2}$ $\left(\mathrm{FiO}_{2}\right)$ of the two patients gradually decreased while the oxygen saturation $\left(\mathrm{SaO}_{2}\right)$ and partial pressure of oxygen $\left(\mathrm{PO}_{2}\right)$ improved. Additionally, the patients' chest computed tomography showed that bilateral lung exudate lesions were adsorbed after MSC infusion. Results indicated that MSC transplantation provides clinical data on the treatment of COVID-19 and may serve as an alternative method for treating COVID-19, particularly in patients with ARDS.
\end{abstract}

Keywords coronavirus disease 2019 (COVID-19); mesenchymal stem cell; acute respiratory distress syndrome; stem cell therapeutics

\section{Introduction}

The coronavirus disease 2019 (COVID-19) caused by SARS-CoV-2 was identified in December 2019 [1-3] and is regarded as a highly infectious epidemic disease [4-6]. As of June 6, 2020, the Chinese National Health Commission reported 84624 confirmed cases and over 4645 deaths. Current epidemiological investigations show that the exposure of many patients can be traced to live seafood and wildlife markets $[7,8]$. Therefore, the host of SARS-CoV-2 could be a wild animal, such as bats,

Received April 26, 2020; accepted June 10, 2020

Correspondence: Charlie Xiang, cxiang@zju.edu.cn; Lanjuan Li, ljli@zju.edu.cn

${ }^{*}$ Lingling Tang, Yingan Jiang, Mengfei Zhu, and Lijun Chen contributed equally to this work. pangolins, poultry, and snakes [9-11]. Although the current epidemic situation in China has been effectively alleviated, an increasing number of countries continue to experience COVID-19 outbreaks [12,13]. Although controlling and preventing epidemics have been an ongoing effort worldwide, the effective treatment of COVID-19 is currently a top priority.

As the outbreak of COVID-19 was sudden, an effective drug for eliminating SARS-CoV-2 has yet to become available, and multiple organ dysfunction in patients with secondary infections remains a serious problem. Several methods for treating COVID-19, including traditional Chinese medicine and western medicine, have been explored. However, the efforts to control acute respiratory distress syndrome (ARDS) through drugs have yet to yield expected results. An autopsy report indicated the cause of death as ARDS and respiratory failure due to viral infection [14]. Pathological sections also revealed that a 
large number of inflammatory factors accumulated in the tissues of the deceased.

Mesenchymal stem cell (MSC)-based therapies have attracted much attention because of their powerful selfrenewal capability and pluripotency $[15,16]$. Currently, MSCs have been widely used in cell therapy, including a large number of basic research and clinical trials [17-19]. Safety and effectiveness have been documented in many clinical trials, especially those dealing with immunemediated inflammatory diseases, such as graft-versus-host disease and systemic lupus erythematosus [20,21]. One of the main functions of MSCs is immune regulation, which can alleviate the inflammatory response in the body through immunosuppression [22-24]. MSCs possess the ability to alleviate inflammatory response and can thus serve as a potential treatment for patients with COVID-19 [25]. Recently, researchers demonstrated no serious adverse events (including hypoxemia, cardiac arrhythmia, and ventricular tachycardia) after the transplantation of allogeneic MSCs in nine patients with ARDS [26].

Menstrual blood is a special source of MSCs, which were initially identified from menstrual blood in 2007 [27]. MSCs derived from menstrual blood are widely studied because of their abundant source, strong proliferation ability, low immunogenicity, and painless surgery without ethical controversy [28-31]. Thus, menstrual bloodderived MSCs have attracted increasing attention, and they have been broadly applied in basic medicine and clinical trials $[32,33]$. Our team has also demonstrated that menstrual blood-derived MSC transplantation is an alternative method for treating ARDS with influenza A (H7N9) infection and thereby reducing mortality relative to controls [34]. As revealed in our five-year follow-up, menstrual blood-derived MSC transplantation did not adversely affect the human body. Therefore, menstrual blood-derived MSC transplantation is also relatively safe, although supporting data remain lacking.

The current study is a clinical pilot study that uses menstrual blood-derived MSCs for the treatment of two patients with severe COVID-19 in Wuhan. The primary endpoints mainly include mortality, nucleic acid detection of SARS-CoV-2, length of hospital stay, and oxygenation indicator after MSC infusion. The secondary endpoints mainly include temperature, blood routine examination, liver function, immune indicator, and inflammation indicator. We found that the oxygenation indicators improved, the immune indicators increased, and a number of inflammation indicators decreased after MSC treatment. Chest computed tomography (CT) showed the adsorption of bilateral lung exudate lesions after MSC transplantation. The two case reports provide a promising way to combat COVID-19, especially in emergency and severe cases. As for the function of MSC transplantation in treating COVID-19, it still needs further verification with many clinical samples and comprehensive assessments.

\section{Source and preparation of MSCs}

The allogeneic, menstrual blood-derived MSCs were prepared from menstrual blood obtained from a healthy female donor (age $=28$ years). The mononuclear cell fraction of the menstrual blood was enriched and tested for nucleated cells, differential, viability, flow cytometry, and sterility prior to seeding for culture. At $70 \%$ confluence, MSCs were lifted and passed at a low density into a cell factory. At 70\%-80\% confluence, the MSCs were washed, harvested, resuspended, and cryopreserved. Karyotyping/ G-banding was normal according to a previous study [35]. The cryopreserved MSCs were shipped frozen to the clinical sites in a validated liquid nitrogen dry shipper equipped with a continuous temperature monitoring device. Upon receipt, the cellular product was inspected and stored in a controlled and continuously monitored liquid nitrogen storage tank. Prior to administration, the MSCs were thawed, washed to remove dimethyl sulfoxide, and resuspended in Plasma-Lyte A by the local cell therapy laboratory. The total volume of the MSC infusion was 100 $\mathrm{mL}$ regardless of dose. The percent viability of the infused MSCs was determined by trypan blue exclusion after the MSCs were thawed and prepared for infusion. The viability ranged from $90 \%$ to $95 \%$. According to the immunophenotype analysis, the menstrual blood-derived MSCs did not express hematopoietic stem cell markers (e.g., CD34, CD45, and CD133) and HLA-DR, but they expressed classical MSC markers (e.g., CD29, CD73, CD90, and CD105) and other surface molecules (e.g., CD9, CD44, and HLA-ABC). The surface maker and three-line differentiation of the MSCs was conducted in accordance with previous studies $[31,35,36]$.

\section{Biological measurements}

Laboratory tests for blood, oxygenation indicators, inflammation indicators, immune indicators, coagulation function, and nucleic acid detection of SARS-CoV-2 were carried out at the Medical Inspection Department of the Renmin Hospital of Wuhan University, Wuhan, China. The other medical information of the patients was retrieved from their medical records. The following factors that could be correlated with the clinical outcomes of the patients with COVID-19 were evaluated: (1) baseline characteristics with regard to age, clinical symptoms, and underlying conditions; (2) related data from laboratory tests and imaging examinations; (3) combined treatments by basic supporting drug, antiviral treatment, antibiotic therapy, glucocorticoid, mechanical ventilation, 
extracorporeal membrane oxygenation, artificial liver support system, and continuous renal replacement therapy. The CONSORT diagram of this clinical trial is shown in Fig. 1.

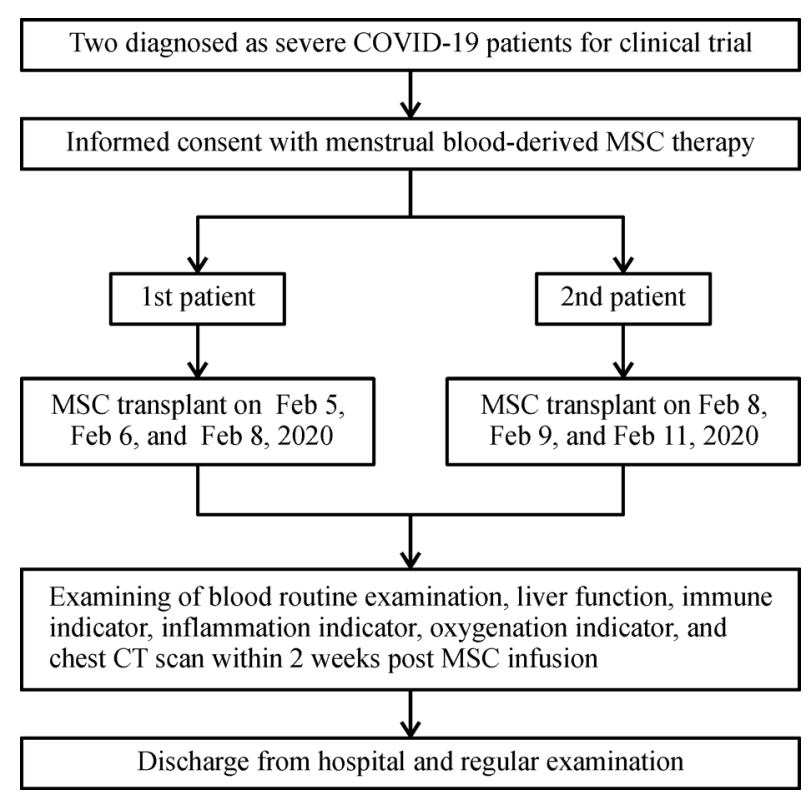

Fig. 1 Detailed CONSORT diagram for the treatment of two patients in our study. The two patients for clinical trial were diagnosed with severe COVID-19. Their informed consent for MSC therapy was obtained accordingly. The first patient received MSC transplant on February 5, February 6, and February 8, 2020. The second patient received MSC transplant on February 8 , February 9, and February 11, 2020. They were then subjected to routine blood examination and tests for liver function, immune indicators, inflammation indicators, oxygenation indicators, and chest CT scan within 2 weeks post-MSC infusion. The two patients were then discharged from the hospital and regularly examined.

\section{Treatment for the two patients}

The allogeneic MSCs were obtained from a healthy female donor (age $=28$ years), who was notified promptly and then subsequently signed a written informed consent. The patients received MSCs. The MSC administration in the patients with COVID-19 was conducted by volunteers, and the participants signed written informed consent forms for the multi-center and open-label clinical trial (No. ChiCTR2000029606). This study was approved by the Ethics Committee of Shulan (Hangzhou) Hospital, Hangzhou, China, and by the Ethics Committee of Renmin Hospital of Wuhan University (No. WDRY2020-K011), Wuhan, China.

\section{Case 1}

A 37-year-old woman presented with fever for 9 days and dyspnea for 4 days and was admitted to the Renmin Hospital of Wuhan University on January 31, 2020. The patient had a history of hypertension for 5 years and had been living in Wuhan for a long time. Physical examination showed fever with a temperature of $38.7^{\circ} \mathrm{C}$, breathing rate of 24 times per minute, and pulse of 118 times per minute. The oxygen saturation $\left(\mathrm{SaO}_{2}\right)$ was $98 \%$, and the partial pressure of oxygen $\left(\mathrm{PO}_{2}\right)$ was $99 \mathrm{mmHg}$ on the basis of $100 \%$ fraction of inspired $\mathrm{O}_{2}\left(\mathrm{FiO}_{2}\right)$. The results of the laboratory examinations (Table 1) showed increased leukocyte count $\left(13.6 \times 10^{9} / \mathrm{L}\right)$, increased neutrophils $(95.0 \%)$, decreased lymphocytes $(4.1 \%)$, and decreased hemoglobin $(72.0 \mathrm{~g} / \mathrm{L})$. On February 4 , before MSC treatment, the inflammatory indicators indicated elevated C-reactive protein (CRP, $42.5 \mathrm{mg} / \mathrm{L}$ ) and increased interleukin-6 (IL-6, $27.1 \mathrm{pg} / \mathrm{mL}$ ). The patient was also tested for cellular immunity and humoral immunity (Table 1). The patient was negative for the following common respiratory pathogens: influenza A virus, mycoplasma pneumonia, respiratory syncytial virus, adenovirus, Chlamydia pneumoniae, Legionella pneumophila, parainfluenza virus, and influenza B virus. She was diagnosed with COVID-19 on the basis of the real-time reverse transcriptase polymerase chain reaction amplification of the viral RNA from a sputum sample.

During hospitalization, oseltamivir, arbidol hydrochloride, lowering of blood pressure, and other symptomatic supportive treatments were given to the patient, but the symptoms of fever and dyspnea did not significantly improve. The infusion was initiated using a standard blood filter tubing set, and the infusion rate was controlled by the investigator on the basis of droplet count. The patient received MSC transplantation through intravenous infusion three times on February 5, 6, and 8, 2020. The injection dose of MSCs was set to 1 million per kg body weight [34]. A multiple intravenous infusion of allogeneic MSCs was well tolerated in the patient with COVID-19.

The symptoms of fever and dyspnea improved (Table 1). $\mathrm{SaO}_{2}$ was $97 \%$, and $\mathrm{PO}_{2}$ was $86 \mathrm{mmHg}$ on the basis of $55 \% \mathrm{FiO}_{2}$ on February 10, 2020. The dynamic changes in laboratory examination are shown in Table 1 . We found that after the MSC treatment, the lymphocytes increased, the inflammation indicators decreased, and the symptom of dyspnea improved (Table 1). The chest X-ray on February 1 and 4 indicated large, patchy, and high-density lesions in the bilateral lungs, and the costal diaphragm angle was not clear (Fig. 2). The X-ray on February 6 and 10 showed the absorption of the exudate lesions in the bilateral lungs (Fig. 2). The patient's nucleic acid test turned negative. A follow-up on the patient was conducted on February 17, 2020. 


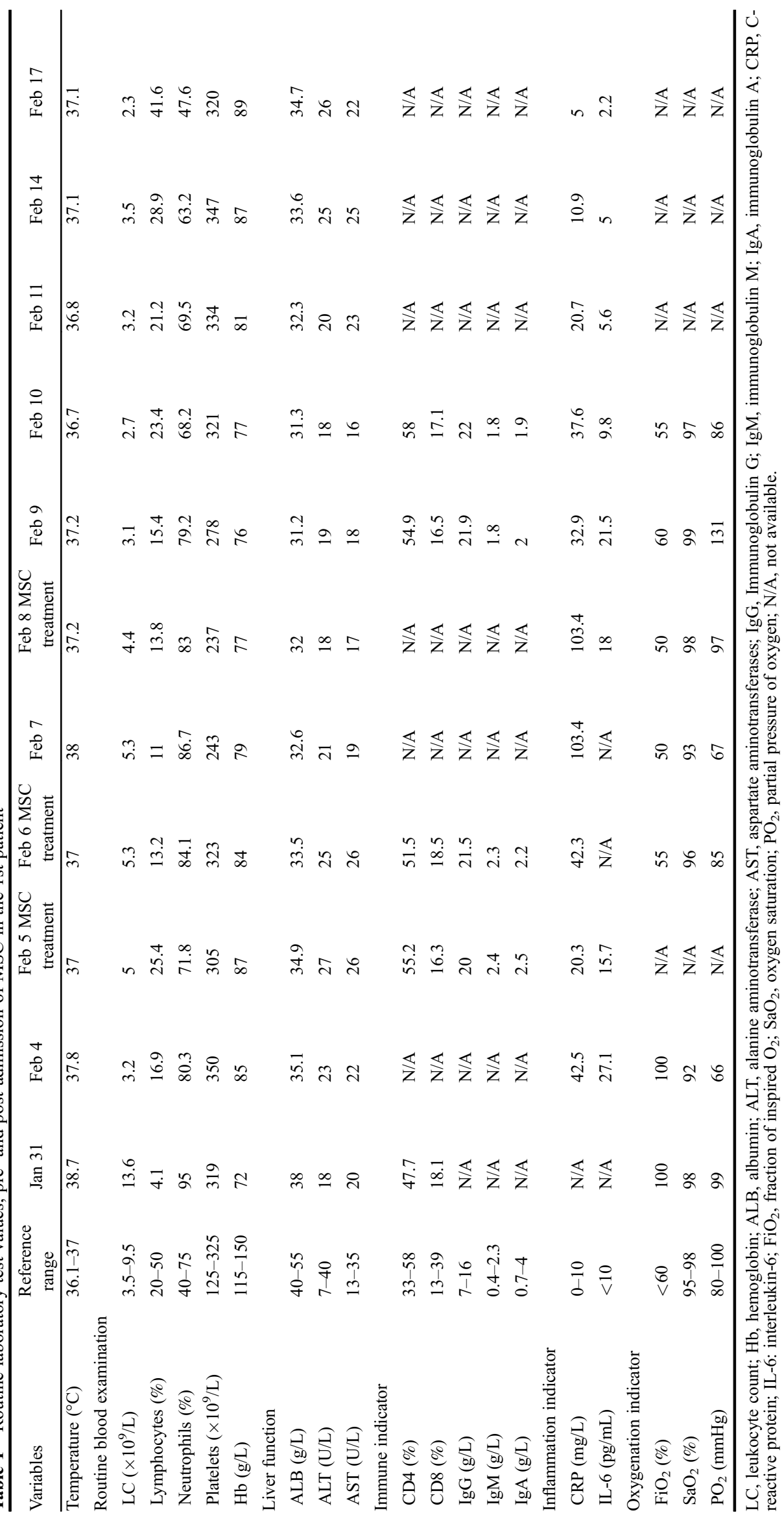




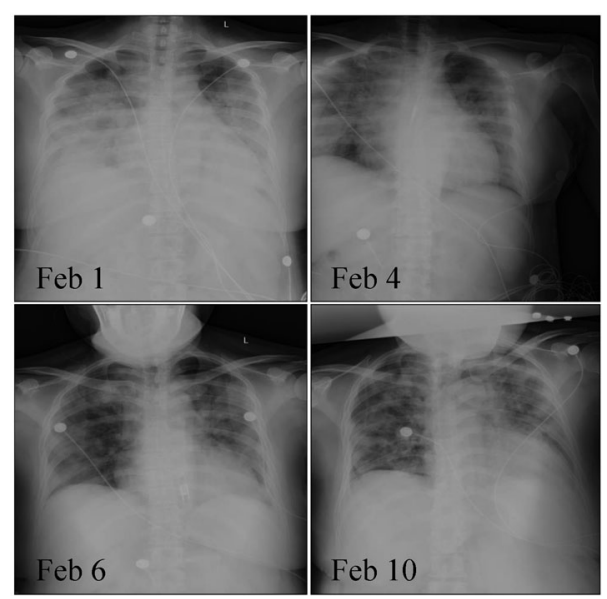

Fig. 2 Chest computerized tomography (CT) images of the first patient. The chest X-ray on February 1 and 4 indicated large, patchy, and highdensity lesions in the bilateral lungs, and the costal diaphragm angle was not clear. The X-ray on February 6 and 10 showed the absorption of the exudate lesions in the bilateral lungs.

\section{Case 2}

A 71-year-old man living in Wuhan, China was diagnosed at Wuhan Seventh People's Hospital on January 28, 2020. The patient presented with fever for 20 days, dyspnea, cough for 10 days, and a body temperature of $39^{\circ} \mathrm{C}$. Then, he presented with dyspnea and cough for 4 days and was admitted to the Renmin Hospital of Wuhan University on February 7, 2020. Physical examination showed dyspnea and cough, a body temperature of $36.5^{\circ} \mathrm{C}$, breathing rate of 34 times per minute, and pulse of 96 times per minute. $\mathrm{SaO}_{2}$ was $98 \%$, and $\mathrm{PO}_{2}$ was $99 \mathrm{mmHg}$ on the basis of $80 \% \mathrm{FiO}_{2}$. The laboratory tests showed a decreased leukocyte count $\left(2.6 \times 10^{9} / \mathrm{L}\right)$, increased neutrophils $(81.3 \%)$, and decreased lymphocytes $(10.5 \%)$ (Table 2$)$. The inflammatory indicators showed elevated CRP (15.5 $\mathrm{mg} / \mathrm{L})$ and normal IL-6 $(5.1 \mathrm{pg} / \mathrm{mL})$. The real-time fluorescence polymerase chain reaction of the patient's sputum was positive for the SARS-CoV-2 nucleic acid. The chest X-ray indicated patchy and high-density shadows in the lower lung fields and the left middle lung (Fig. 3).

During hospitalization, ribavirin, arbidol hydrochloride, cefoperazone-sulbactam, lowering of blood pressure, and other symptomatic supportive treatments were given to the patient. At the same time, the patient received MSC treatment via intravenous infusion three times on February 8, 9, and 11, 2020. The injection dose of MSCs was determined as 1 million per $\mathrm{kg}$ body weight [34]. A multiple intravenous infusion of allogeneic MSCs was well tolerated in the patient with SARS-CoV-2-induced ARDS. $\mathrm{SaO}_{2}$ was $99 \%$, and $\mathrm{PO}_{2}$ was $169 \mathrm{mmHg}$ on the basis of $30 \%$ oxygen concentration on February 15, 2020. The dynamic changes in the laboratory examination are shown in Table 2. We found that after the MSC treatment, the lymphocytes increased, the inflammation indicators, especially CRP, decreased, and $\mathrm{FiO}_{2}$ declined (Table 2). Repeat chest X-ray showed the absorption of high-density exudate in the lower lung fields and left middle lung (Fig. 3). The expression of SARS-CoV-2 was negative according to the test of nucleic acid on February 16 and 19, 2020. A followup on the patient was conducted on February 22, 2020.

\section{Discussion}

SARS-CoV-2 infections are clinically similar to previous SARS-CoV and MERS-CoV infections [37,38]. The initial symptoms usually include fever, cough, shortness of breath, early symptom of sputum, and ARDS, which leads to lung injuries and pulmonary fibrosis $[39,40]$. Although about $20 \%-25 \%$ of people infected with MERSCoV or SARS-CoV have diarrhea, patients with COVID19 rarely have bowel symptoms [41,42]. This result implies that as long as the breathing difficulties of patients with COVID-19 are addressed quickly, their own immune system may recover on their own or with the aid of immunostimulants; then, they can successfully resist further virus invasion. However, in another study of 99 patients, chest pain, confusion, and nausea and vomiting were found, in addition to previous findings [43]. X-rays or chest CT images with unilateral or bilateral involvement revealed compatibility with viral pneumonia; moreover, bilateral multilobular and subsegmental consolidation areas were observed in the chest in the intensive care unit $[1,44]$. Further autopsy reports showed a large amount of sputum, which caused severe ARDS, while a pathological examination indicated a good deal of inflammatory factors in the lung tissue of the patient [14]. Therefore, effectively controlling the inflammatory factors would be a key to treating COVID-19. Early studies have reported that MSC transplantation may promote lung repair and regulate the process of inflammation to reduce fibrosis $[45,46]$. Thus, MSCs have a great potential in terms of their immunomodulatory effects and attenuation of inflammatory responses.

CRP is a typical acute phase serum protein, which rapidly rises in inflammatory response. CRP, especially tumor necrosis factor $\alpha(\mathrm{TNF} \alpha)$, IL-6, monocyte chemoattractant protein-1 (MCP-1), and IL-8 secreted by T cells, are highly sensitive biomarkers of inflammation and host response [47]. Several reports have focused on lymphopenia and high levels of CRP in COVID-19 patients $[3,6,48]$. In our study, we found that after the MSC treatment, the lymphocytes increased, the inflammation indicators (CRP and IL-6) decreased, and the symptom of dyspnea improved after MSC and antiviral treatment. High-flow nasal cannula (HFNC) can be used as an initial 


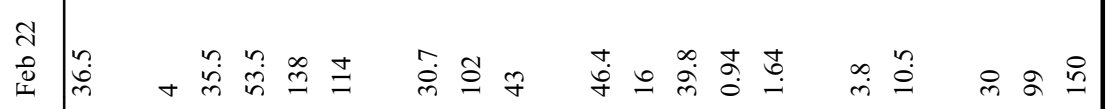

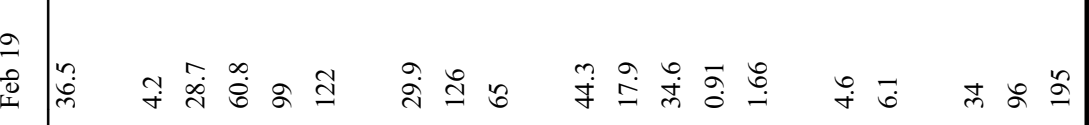

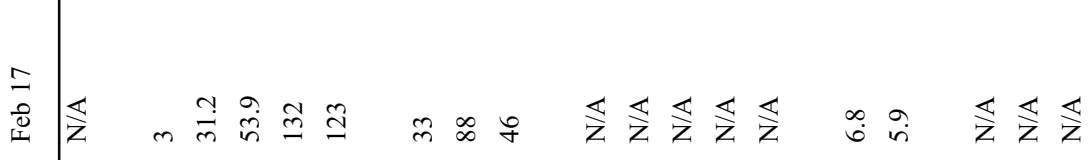

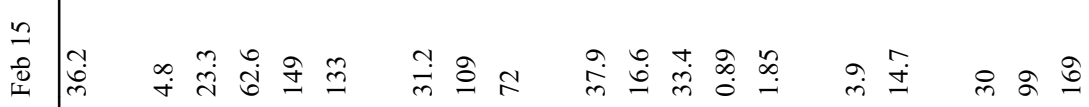

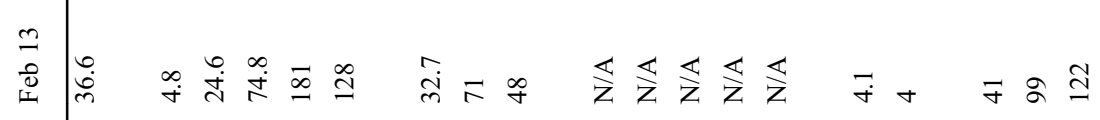

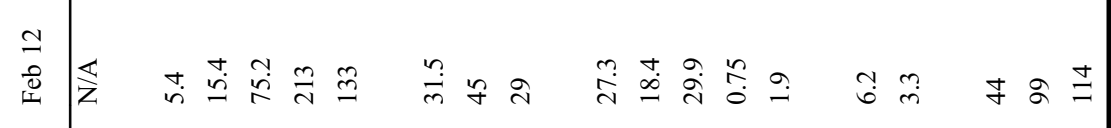
$\sum_{\substack{n \\ \text { a }}}$

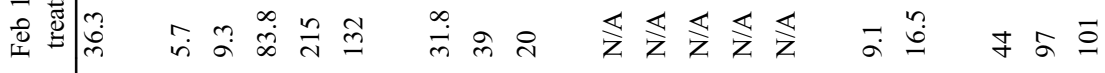
葡 


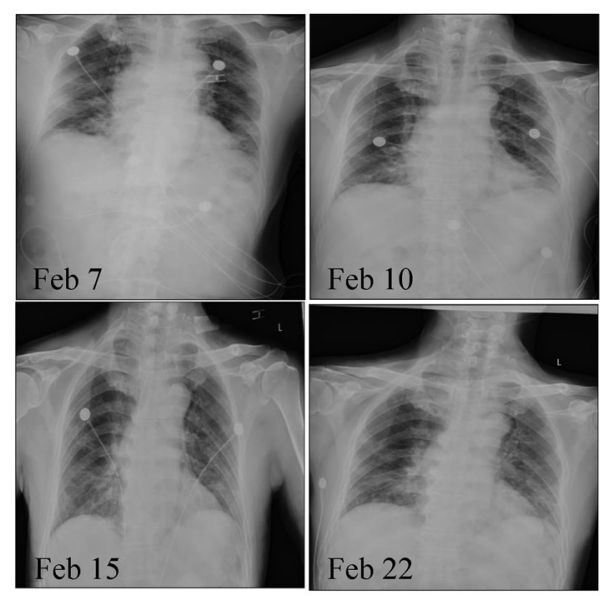

Fig. 3 Chest CT images of second patient. The chest X-ray on February 7 and 10 indicated patchy and high-density shadows in the lower lung fields and the left middle lung. Repeat chest X-ray on February 15 and 22 showed that high-density exudate was absorbed in the lower lung fields and the left middle lung.

support strategy for patients with ARDS. Both patients with symptoms of acute respiratory distress at admission were given HFNC over 50\%. With the MSC and antiviral treatment, the $\mathrm{FiO}_{2}$ of the two patients gradually decreased while $\mathrm{SaO}_{2}$ and $\mathrm{PO}_{2}$ returned to normal. Consistent with other studies, the early administration of MSCs significantly reduced the damage of the lung architecture and inflammatory cell infiltration [49]. Thus, MSCs may inhibit the inflammatory effect to relieve the symptoms of COVID-19.

In our previous report, 17 patients received MSC treatment for H7N9 infection [34]; 4 of these patients received a five-year follow-up and did not show evident adverse reactions. From the two reported cases in the current work, we also did not find obvious adverse reactions in our short-term clinical research. However, whether MSC infusion will cause infusion reaction or transient shortness of breath still requires further data and comprehensive research. Recently, Leng et al. published a clinical paper about MSC treatment for COVID-19 patients [48]; they used seven enrolled patients to investigate the inflammatory and immune function of adverse effects for 14 days post MSC transplantation. Then, they found that MSC could significantly remit the functional outcomes of the patients without observed adverse effects. Therefore, we need extensive clinical data to identify whether or not short-term adverse reactions occur after MSC administration. Currently, no evidence proves that MSC is associated with long-term adverse events. Zheng et al. proved no obvious toxicities or seriously adverse events after MSC infusion for 12 patients with moderate to severe ARDS in a single-center, randomized, double-blind, and placebo-controlled trial
[50]. Our previous study also showed that menstrual blood-derived MSCs exerted no obvious side effects according to a five-year follow-up of four MSC patients [34]. Although the tolerability and safety of MSC transplantation in patients lack long-term follow-up, it is still an imperative way to treat COVID-19, especially severe cases.

Zhang and Ma reported that the COVID-19 pandemic had a mild stressful impact on the mental health and quality of life of local Chinese residents in Liaoning Province [51]. Currently, no study has reported the quality of life of COVID-19 patients after hospital discharge. Therefore, we suggest that the quality of life of COVID-19 survivors can be studied in the future to assess the impact of the COVID19 pandemic.

This clinical trial has several limitations. For example, only 2 patients received MSC treatment; the sample size is thus too small. Therefore, we can neither generalize our phase one experience nor draw conclusions about either the efficacy or long-term safety of MSCs as treatment for COVID-19. As a large proportion of patients live far from Hangzhou City (Wuhan City), the transportation of MSCs is a big issue. In this trial, although the function of MSCs offers a great perspective in treating COVID-19, extensive clinical data are still needed to support their use in future clinical medicine.

\section{Summary}

This work offers several clues about MSC-based therapy for combating COVID-19. First, we hope that other types of MSCs (such as menstrual blood-derived MSCs) can be preserved in advance in local cell banks for use in emergencies. Second, the variation tendencies of lymphocytes, $\mathrm{CRP}$, and $\mathrm{FiO}_{2}$ are the same for both patients in this work; these indicators may be reacted first and should be monitored for future clinical research using MSC therapy. Third, combined with our previous experience and this case study [34], multiple injections (about three times) are appropriate.

Along with our previous studies [34,52], the current work shows that MSCs can improve lung function through anti-inflammatory effects on injured lungs. Although the clinical research of menstrual blood-derived MSCs is still in its infancy, we believe that MSCs will be a promising tool for future clinical medicine.

\section{Acknowledgements}

The authors thank Dr. Shusen Zheng and Dr. Tingbo Liang from The First Affiliated Hospital, College of Medicine, Zhejiang University for support of this work. This work was supported by the Technological Special Project for Significant New Drugs Development of China (No. 2018ZX09201002-005) and National Key R\&D 
Program of China (No. 2017YFA0105701), the National Science and Technology Major Project (No. 2017ZX10204401), and the Emergency Research Fund for COVID-19 of Zhejiang Province (No. 2020C03125).

\section{Compliance with ethics guidelines}

Lingling Tang, Yingan Jiang, Mengfei Zhu, Lijun Chen, Xiaoyang Zhou, Chenliang Zhou, Peng Ye, Xiaobei Chen, Baohong Wang, Zhenyu Xu, Qiang Zhang, Xiaowei Xu, Hainv Gao, Xiaojun Wu, Dong Li, Wanli Jiang, Jingjing Qu, Charlie Xiang, and Lanjuan Li declare no conflicts of interest. This study was approved by the Ethics Committee of Shulan (Hangzhou) hospital, Hangzhou, China and the Ethics Committee of Renmin Hospital of Wuhan University (No. WDRY2020-K011), Wuhan, China. MSC administration in patients with SARS-CoV-2 induced ARDS was conducted in a multi-center and open-label clinical trial (No. ChiCTR2000029606).

\section{References}

1. Huang C, Wang Y, Li X, Ren L, Zhao J, Hu Y, Zhang L, Fan G, Xu J, Gu X, Cheng Z, Yu T, Xia J, Wei Y, Wu W, Xie X, Yin W, Li H, Liu M, Xiao Y, Gao H, Guo L, Xie J, Wang G, Jiang R, Gao Z, Jin Q, Wang J, Cao B. Clinical features of patients infected with 2019 novel coronavirus in Wuhan, China. Lancet 2020; 395(10223): 497506

2. Li Q, Guan X, Wu P, Wang X, Zhou L, Tong Y, Ren R, Leung KSM, Lau EHY, Wong JY, Xing X, Xiang N, Wu Y, Li C, Chen Q, Li D, Liu T, Zhao J, Liu M, Tu W, Chen C, Jin L, Yang R, Wang Q, Zhou S, Wang R, Liu H, Luo Y, Liu Y, Shao G, Li H, Tao Z, Yang Y, Deng Z, Liu B, Ma Z, Zhang Y, Shi G, Lam TTY, Wu JT, Gao GF, Cowling BJ, Yang B, Leung GM, Feng Z. Early transmission dynamics in Wuhan, China, of novel coronavirus-infected pneumonia. N Engl J Med 2020; 382(13): 1199-1207

3. Xu XW, Wu XX, Jiang XG, Xu KJ, Ying LJ, Ma CL, Li SB, Wang HY, Zhang S, Gao HN, Sheng JF, Cai HL, Qiu YQ, Li LJ. Clinical findings in a group of patients infected with the 2019 novel coronavirus (SARS-CoV-2) outside of Wuhan, China: retrospective case series. BMJ 2020; 368: m606

4. Holshue ML, DeBolt C, Lindquist S, Lofy KH, Wiesman J, Bruce H, Spitters C, Ericson K, Wilkerson S, Tural A, Diaz G, Cohn A, Fox L, Patel A, Gerber SI, Kim L, Tong S, Lu X, Lindstrom S, Pallansch MA, Weldon WC, Biggs HM, Uyeki TM, Pillai SK; Washington State 2019-nCoV Case Investigation Team. First case of 2019 novel coronavirus in the United States. N Engl J Med 2020; 382(10): 929-936

5. Xia S, Liu M, Wang C, Xu W, Lan Q, Feng S, Qi F, Bao L, Du L, Liu S, Qin C, Sun F, Shi Z, Zhu Y, Jiang S, Lu L. Inhibition of SARS-CoV-2 (previously 2019-nCoV) infection by a highly potent pan-coronavirus fusion inhibitor targeting its spike protein that harbors a high capacity to mediate membrane fusion. Cell Res 2020; 30: 343-355

6. Guan WJ, Ni ZY, Hu Y, Liang WH, Ou CQ, He JX, Liu L, Shan H, Lei CL, Hui DSC, Du B, Li LJ, Zeng G, Yuen KY, Chen RC, Tang CL, Wang T, Chen PY, Xiang J, Li SY, Wang JL, Liang ZJ, Peng
YX, Wei L, Liu Y, Hu YH, Peng P, Wang JM, Liu JY, Chen Z, Li G, Zheng ZJ, Qiu SQ, Luo J, Ye CJ, Zhu SY, Zhong NS; China Medical Treatment Expert Group for COVID-19. Clinical characteristics of coronavirus disease 2019 in China. N Engl J Med 2020; 382(18): 1708-1720

7. Zhou M, Zhang X, Qu J. Coronavirus disease 2019 (COVID-19): a clinical update. Front Med 2020; 14(2): 126-135

8. Zhou P, Yang XL, Wang XG, Hu B, Zhang L, Zhang W, Si HR, Zhu Y, Li B, Huang CL, Chen HD, Chen J, Luo Y, Guo H, Jiang RD, Liu MQ, Chen Y, Shen XR, Wang X, Zheng XS, Zhao K, Chen QJ, Deng F, Liu LL, Yan B, Zhan FX, Wang YY, Xiao GF, Shi ZL. A pneumonia outbreak associated with a new coronavirus of probable bat origin. Nature 2020; 579(7798): 270-273

9. Lu H, Stratton CW, Tang YW. Outbreak of pneumonia of unknown etiology in Wuhan, China: the mystery and the miracle. J Med Virol 2020; 92(4): 401-402

10. Lu R, Zhao X, Li J, Niu P, Yang B, Wu H, Wang W, Song H, Huang B, Zhu N, Bi Y, Ma X, Zhan F, Wang L, Hu T, Zhou H, Hu Z, Zhou W, Zhao L, Chen J, Meng Y, Wang J, Lin Y, Yuan J, Xie Z, Ma J, Liu WJ, Wang D, Xu W, Holmes EC, Gao GF, Wu G, Chen W, Shi W, Tan W. Genomic characterisation and epidemiology of 2019 novel coronavirus: implications for virus origins and receptor binding. Lancet 2020; 395(10224): 565-574

11. Zhang Q, Wang Y, Qi C, Shen L, Li J. Clinical trial analysis of 2019nCoV therapy registered in China. J Med Virol 2020; 92(6): 540545

12. Rothan HA, Byrareddy SN. The epidemiology and pathogenesis of coronavirus disease (COVID-19) outbreak. J Autoimmun 2020; 109: 102433

13. Wang C, Horby PW, Hayden FG, Gao GF. A novel coronavirus outbreak of global health concern. Lancet 2020; 395(10223): 470473

14. Xu Z, Shi L, Wang Y, Zhang J, Huang L, Zhang C, Liu S, Zhao P, Liu H, Zhu L, Tai Y, Bai C, Gao T, Song J, Xia P, Dong J, Zhao J, Wang FS. Pathological findings of COVID-19 associated with acute respiratory distress syndrome. Lancet Respir Med 2020; 8(4): 420422

15. Han Y, Li X, Zhang Y, Han Y, Chang F, Ding J. Mesenchymal stem cells for regenerative medicine. Cells 2019; 8(8): E886

16. Le Blanc K, Davies LC. MSCs-cells with many sides. Cytotherapy 2018; 20(3): 273-278

17. Shi M, Liu Z, Wang Y, Xu R, Sun Y, Zhang M, Yu X, Wang H, Meng L, Su H, Jin L, Wang FS. A pilot study of mesenchymal stem cell therapy for acute liver allograft rejection. Stem Cells Transl Med 2017; 6(12): 2053-2061

18. Weiss ARR, Dahlke MH. Immunomodulation by mesenchymal stem cells (MSCs): mechanisms of action of living, apoptotic, and dead MSCs. Front Immunol 2019; 10: 1191

19. Samsonraj RM, Raghunath M, Nurcombe V, Hui JH, van Wijnen AJ, Cool SM. Concise review: multifaceted characterization of human mesenchymal stem cells for use in regenerative medicine. Stem Cells Transl Med 2017; 6(12): 2173-2185

20. Hashmi S, Ahmed M, Murad MH, Litzow MR, Adams RH, Ball LM, Prasad VK, Kebriaei P, Ringden O. Survival after mesenchymal stromal cell therapy in steroid-refractory acute graft-versushost disease: systematic review and meta-analysis. Lancet Haematol 2016; 3(1): e45-e52 
21. Liang J, Zhang H, Kong W, Deng W, Wang D, Feng X, Zhao C, Hua B, Wang H, Sun L. Safety analysis in patients with autoimmune disease receiving allogeneic mesenchymal stem cells infusion: a long-term retrospective study. Stem Cell Res Ther 2018; 9(1): 312

22. Gao F, Chiu SM, Motan DA, Zhang Z, Chen L, Ji HL, Tse HF, Fu QL, Lian Q. Mesenchymal stem cells and immunomodulation: current status and future prospects. Cell Death Dis 2016; 7(1): e2062

23. de Castro LL, Lopes-Pacheco M, Weiss DJ, Cruz FF, Rocco PRM. Current understanding of the immunosuppressive properties of mesenchymal stromal cells. J Mol Med (Berl) 2019; 97(5): 605-618

24. Saldaña L, Bensiamar F, Vallés G, Mancebo FJ, García-Rey E, Vilaboa N. Immunoregulatory potential of mesenchymal stem cells following activation by macrophage-derived soluble factors. Stem Cell Res Ther 2019; 10(1): 58

25. Khoury M, Rocco PRM, Phinney DG, Krampera M, Martin I, Viswanathan S, Nolta JA, LeBlanc K, Galipeau J, Weiss DJ. Cellbased therapies for COVID-19: proper clinical investigations are essential. Cytotherapy 2020; [Epub ahead of print] doi: 10.1016/j. jcyt.2020.04.089

26. Wilson JG, Liu KD, Zhuo H, Caballero L, McMillan M, Fang X, Cosgrove K, Vojnik R, Calfee CS, Lee JW, Rogers AJ, Levitt J, Wiener-Kronish J, Bajwa EK, Leavitt A, McKenna D, Thompson BT, Matthay MA. Mesenchymal stem (stromal) cells for treatment of ARDS: a phase 1 clinical trial. Lancet Respir Med 2015; 3(1): 24 32

27. Meng X, Ichim TE, Zhong J, Rogers A, Yin Z, Jackson J, Wang H, Ge W, Bogin V, Chan KW, Thébaud B, Riordan NH. Endometrial regenerative cells: a novel stem cell population. J Transl Med 2007; 5(1): 57

28. Zuo W, Xie B, Li C, Yan Y, Zhang Y, Liu W, Huang J, Chen D. The clinical applications of endometrial mesenchymal stem cells. Biopreserv Biobank 2018; 16(2): 158-164

29. Chen L, Qu J, Xiang C. The multi-functional roles of menstrual blood-derived stem cells in regenerative medicine. Stem Cell Res Ther 2019; 10(1): 1

30. Yan Z, Guo F, Yuan Q, Shao Y, Zhang Y, Wang H, Hao S, Du X. Endometrial mesenchymal stem cells isolated from menstrual blood repaired epirubicin-induced damage to human ovarian granulosa cells by inhibiting the expression of Gadd $45 \mathrm{~b}$ in cell cycle pathway. Stem Cell Res Ther 2019; 10(1): 4

31. Chen L, Zhang C, Chen L, Wang X, Xiang B, Wu X, Guo Y, Mou X, Yuan L, Chen B, Wang J, Xiang C. Human menstrual bloodderived stem cells ameliorate liver fibrosis in mice by targeting hepatic stellate cells via paracrine mediators. Stem Cells Transl Med 2017; 6(1): 272-284

32. Khanmohammadi M, Khanjani S, Edalatkhah H, Zarnani AH, Heidari-Vala H, Soleimani M, Alimoghaddam K, Kazemnejad S. Modified protocol for improvement of differentiation potential of menstrual blood-derived stem cells into adipogenic lineage. Cell Prolif 2014; 47(6): 615-623

33. Chen L, Qu J, Cheng T, Chen X, Xiang C. Menstrual blood-derived stem cells: toward therapeutic mechanisms, novel strategies, and future perspectives in the treatment of diseases. Stem Cell Res Ther 2019; 10(1): 406

34. Chen J, Hu C, Chen L, Tang L, Zhu Y, Xu X, Chen L, Gao H, Lu X, Yu L, Dai X, Xiang C, Li L. Clinical study of mesenchymal stem cell treating acute respiratory distress syndrome induced by epidemic influenza A (H7N9) infection, a hint for COVID-19 treatment. Engineering (Beijing) 2020; [Epub ahead of print] doi: 10.1016/j.eng.2020.02.006

35. Wu X, Luo Y, Chen J, Pan R, Xiang B, Du X, Xiang L, Shao J, Xiang C. Transplantation of human menstrual blood progenitor cells improves hyperglycemia by promoting endogenous progenitor differentiation in type 1 diabetic mice. Stem Cells Dev 2014; 23(11): 1245-1257

36. Wu Y, Chen X, Zhao Y, Wang Y, Li Y, Xiang C. Genome-wide DNA methylation and hydroxymethylation analysis reveal human menstrual blood-derived stem cells inhibit hepatocellular carcinoma growth through oncogenic pathway suppression via regulating 5hmC in enhancer elements. Stem Cell Res Ther 2019; 10(1): 151

37. Li YH, Hu CY, Wu NP, Yao HP, Li LJ. Molecular characteristics, functions, and related pathogenicity of MERS-CoV proteins. Engineering (Beijing) 2019; 5(5): 940-947

38. Bosch BJ, Martina BE, Van Der Zee R, Lepault J, Haijema BJ, Versluis C, Heck AJ, De Groot R, Osterhaus AD, Rottier PJ. Severe acute respiratory syndrome coronavirus (SARS-CoV) infection inhibition using spike protein heptad repeat-derived peptides. Proc Natl Acad Sci USA 2004; 101(22): 8455-8460

39. Chen G, Wu D, Guo W, Cao Y, Huang D, Wang H, Wang T, Zhang X, Chen H, Yu H, Zhang X, Zhang M, Wu S, Song J, Chen T, Han M, Li S, Luo X, Zhao J, Ning Q. Clinical and immunological features of severe and moderate coronavirus disease 2019. J Clin Invest 2020; 130(5): 2620-2629

40. The Lancet. Emerging understandings of 2019-nCoV. Lancet 2020; 395(10221): 311

41. Cohen J, Normile D. New SARS-like virus in China triggers alarm. Science 2020; 367(6475): 234-235

42. Lorusso A, Calistri P, Petrini A, Savini G, Decaro N. Novel coronavirus (SARS-CoV-2) epidemic: a veterinary perspective. Vet Ital 2020; 56(1): 5-10

43. Chen N, Zhou M, Dong X, Qu J, Gong F, Han Y, Qiu Y, Wang J, Liu Y, Wei Y, Xia J, Yu T, Zhang X, Zhang L. Epidemiological and clinical characteristics of 99 cases of 2019 novel coronavirus pneumonia in Wuhan, China: a descriptive study. Lancet 2020; 395(10223): 507-513

44. Zhu N, Zhang D, Wang W, Li X, Yang B, Song J, Zhao X, Huang B, Shi W, Lu R, Niu P, Zhan F, Ma X, Wang D, Xu W, Wu G, Gao GF, Tan W; China Novel Coronavirus Investigating and Research Team. A novel coronavirus from patients with pneumonia in China, 2019. N Engl J Med 2020; 382(8): 727-733

45. Chen S, Cui G, Peng C, Lavin MF, Sun X, Zhang E, Yang Y, Guan Y, Du Z, Shao H. Transplantation of adipose-derived mesenchymal stem cells attenuates pulmonary fibrosis of silicosis via antiinflammatory and anti-apoptosis effects in rats. Stem Cell Res Ther 2018; 9(1): 110

46. Liu D, Kong F, Yuan Y, Seth P, Xu W, Wang H, Xiao F, Wang L, Zhang Q, Yang Y, Wang H. Decorin-modified umbilical cord mesenchymal stem cells (MSCs) attenuate radiation-induced lung injuries via regulating inflammation, fibrotic factors, and immune responses. Int J Radiat Oncol Biol Phys 2018; 101(4): 945-956

47. Marnell L, Mold C, Du Clos TW. C-reactive protein: ligands, receptors and role in inflammation. Clin Immunol 2005; 117(2): $104-111$

48. Leng Z, Zhu R, Hou W, Feng Y, Yang Y, Han Q, Shan G, Meng F, 
Du D, Wang S, Fan J, Wang W, Deng L, Shi H, Li H, Hu Z, Zhang F, Gao J, Liu H, Li X, Zhao Y, Yin K, He X, Gao Z, Wang Y, Yang B, Jin R, Stambler I, Lim LW, Su H, Moskalev A, Cano A, Chakrabarti S, Min KJ, Ellison-Hughes G, Caruso C, Jin K, Zhao RC. Transplantation of ACE2 ${ }^{-}$mesenchymal stem cells improves the outcome of patients with COVID-19 pneumonia. Aging Dis 2020; 11(2): 216-228

49. Cahill EF, Kennelly H, Carty F, Mahon BP, English K. Hepatocyte growth factor is required for mesenchymal stromal cell protection against bleomycin-induced pulmonary fibrosis. Stem Cells Transl Med 2016; 5(10): 1307-1318

50. Zheng G, Huang L, Tong H, Shu Q, Hu Y, Ge M, Deng K, Zhang L,
Zou B, Cheng B, Xu J. Treatment of acute respiratory distress syndrome with allogeneic adipose-derived mesenchymal stem cells: a randomized, placebo-controlled pilot study. Respir Res 2014; 15(1): 39

51. Zhang Y, Ma ZF. Impact of the COVID-19 pandemic on mental health and quality of life among local residents in Liaoning Province, China: a cross-sectional study. Int J Environ Res Public Health 2020; 17(7): E2381

52. Xiang $\mathrm{B}$, Chen $\mathrm{L}$, Wang $\mathrm{X}$, Zhao $\mathrm{Y}$, Wang $\mathrm{Y}$, Xiang $\mathrm{C}$. Transplantation of menstrual blood-derived mesenchymal stem cells promotes the repair of LPS-induced acute lung injury. Int J Mol Sci 2017; 18(4): 689 